\title{
НЕСТАНДАРТНЫЕ ПРИБОРЫ ДЛЯ ОПРЕДЕЛЕНИЯ ТЕМПЕРАТУРНЫХ ПРЕДЕЛОВ ВОСПЛАМЕНЕНИЯ
}

\author{
С. Г. Алексеев, К. С. Алексеев, В. В. Смирнов, Н. М. Барбин
}

СЕРГЕЙ ГЕННАДЬЕВИЧ АЛЕКСЕЕВ - кандидат химических наук, доиент, научный консультант автономной некоммерческой организации «Уральский научно-исследовательский институт Bсероссийского добровольного пожарного общества»,E-mail: 3608113@mail.ru.

КИРИЛЛ СЕРГЕЕВИЧ АЛЕКСЕЕВ - кандидат технических наук, преподаватель кафедры химии, почвоведения $u$ агроэкологии Уральского государственного аграрного университета, E-mail: paradox2405@mail.ru.

ВИТАЛИЙ ВЛАДИМИРОВИЧ СМИРНОВ - старший преподаватель кафедры пожарная безопасность в строительстве Уральского института государственной противопожарной службы МЧС России, E-mail: s_vitaly2006@list.ru.

НИКОЛАЙ МИХАЙЛОВИЧ БАРБИН - доктор технических наук, доичент, ведущзий научный сотрудник научно-исследовательского отдела Уральского института государственной противопожарной службы MЧC Poccuu, E-mail: NMBarbin@mail.ru.

620137, Свердловская область, г. Екатеринбург, ул. Учителей 32. АНО «Уральскийнаучно-исследовательский институт ВДПО».

620075 Свердловская область, г. Екатеринбург, ул. Карла Либкнехта, д. 42. Уральский государственныий сельскохозяйственный университет.

620062, Свердловская область, г. Екатеринбург, ул. Мира, д. 22. Уральский институт ГПС МЧС России.

Температурные предель воспламенения являются одними из ключевых показателей пожаровзрывоопасности и применяются при разработке мероприятий по обеспечению пожаровзрывобезопасности производственных объектов, используются при расчете безопасных температурных режимов для хранения, транспортировки и переработки легковоспламеняющихся и горючих жидкостей. Наряду со стандартными методами определения температурных пределов воспламенения исследователями применяются нестандартные приборы. В работе рассмотрены аппараты Этнера, Брэдли-Хэйла, Мака, Фрике, Джонса, американского горного бюро, исследовательской лаборатории ВМФ США, ЦНИИПО (ВНИИПО), Ягуи, Гордона, Конга, Хасегава-Кашики, Брандес и 20 литровая сферическая бомба. Показано, что во многих случаях нестандартные приборы позволяют определять температурные предель воспламенения с приемлемой точностью.

Ключевые слова: нижний (верхний) температурный предел воспламенения, нижняя (верхняя) температура взрыва, низшая (верхняя) температура вспышки, показатель пожаровзрывоопасности. 


\title{
NON-STANDARD APPARATUSES FOR DETERMINING TEMPERATURE FLAMMABILITY LIMITS
}

\author{
S. G. Alexeev ${ }^{\mathrm{a}}$ K.S. Alexeev ${ }^{\mathrm{b}}$, V.V. Smirnov ${ }^{\mathrm{c}}$, N.M. Barbin \\ ${ }^{a}$ Research Department, Ural Research Institute of the All-Russian Voluntary Fire Society, 32-407 Ucheteley Str., \\ Yekaterunburg, Russia, 620137. \\ ${ }^{b}$ Department of Chemistry, Soil Science and Agroecology, Ural State Agrarian University, 42 Karl Liebknecht Str., \\ Yekaterunburg, Russia, 620075.
}

'Ural State Fire Service Institute of Emercom of Russia, 22 Mira Str., Yekaterunburg, Russia, 620062.

The temperature flammability limits are the key indicators of fire and explosion hazard and are used in the development of measures to ensure fire and explosion safety of industrial facilities. They are applied in calculating safe temperature conditions for storage, transportation and processing of flammable and combustible liquids. Researchers are enforced non-standard devices to determine the temperature limits of ignition along with standard methods. The paper considers the devices of Eitner, Bradley-Hale, Mack, Fricke, Jones, US Bureau of mines, Naval Research Laboratory of Department of the Navy of US, TzNIIPO (VNIIPO), Yagyu, Gordon, Kong, HasegawaKashiki, Brandes, and a 20-liter spherical bomb. There are non-standard devices make it possible to determine the temperature flammability limits with acceptable accuracy in many cases.

Keywords: lower (upper) flammability temperature limit, lower (upper) explosion point, lower (upper) flash point, fire and explosion hazard characteristic

\section{Введение}

Под нижним (верхним) температурным пределом воспламенения (далее НТПВ и ВТПВ) понимается температура, при которой образуется концентрация насыщенного пара, равная нижнему (верхнему) концентрационному пределу воспламенения (далее НКПВ и ВКПВ) [1-4]. Следует отметить, что в технической литературе вместо НТПВ и ВТПВ (lower and upper temperature limits of flammability) используются также синонимы. В нашей стране и странах СНГ - нижний (верхний) температурный предел распространения пламени, в Западном мире - нижняя (верхняя) температура взрыва (lower (upper) explosion point), нижняя (верхняя) температура вспышки (lower (upper) flash point).

Значения температурных пределов воспламенения (далее ТПВ) применяются при разработке мероприятий по обеспечению пожаровзрывобезопасности производственных объектов, используются при расчете температурных режимов для хранения, транспортировки и переработки легковоспламеняющихся и горючих жидкостей (далее ЛВЖ и ГЖ).
В настоящее время стандартные приборы и методы для определения ТПВ разработаны в России, Западной Европе и США (рис. 1-3) [1-3, 6], причем американский нормативный документ ограничивается только экспериментальной методикой для НТПВ.

Однако наряду со стандартными приборами и методами существуют и нестандартные экспериментальные подходы для определения ТПВ, которые явились предметом настоящего обзора.

\section{Предпосылки для приборов и методов для определения ТПВ}

Истоки возникновения методов определения ТПВ берут свое начало от начального этапа керосиновой эры, когда различные способы определения температуры вспышки (далее ТВ) керосина и других продуктов активно разрабатывались и апробировались. С формальной точки зрения все методы определения ТВ, разработанные до начала 20-го столетия можно считать, как попытки определения НТПВ, поскольку считалось, что вспышка ЛВЖ/ ГЖ происходит на НКПВ [7-10]. На основе этой гипотезы возник полуэмпирический метод опреде- 


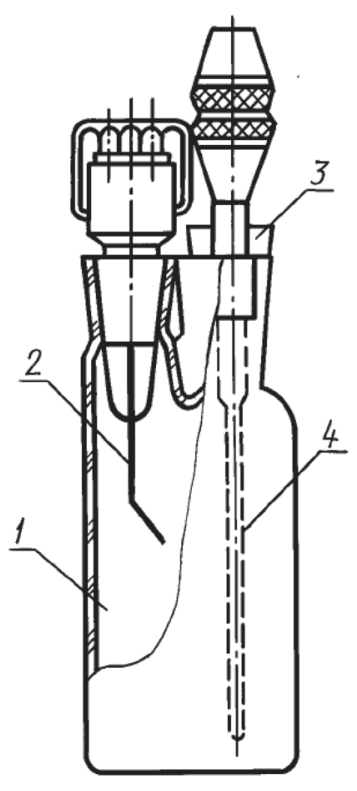

a

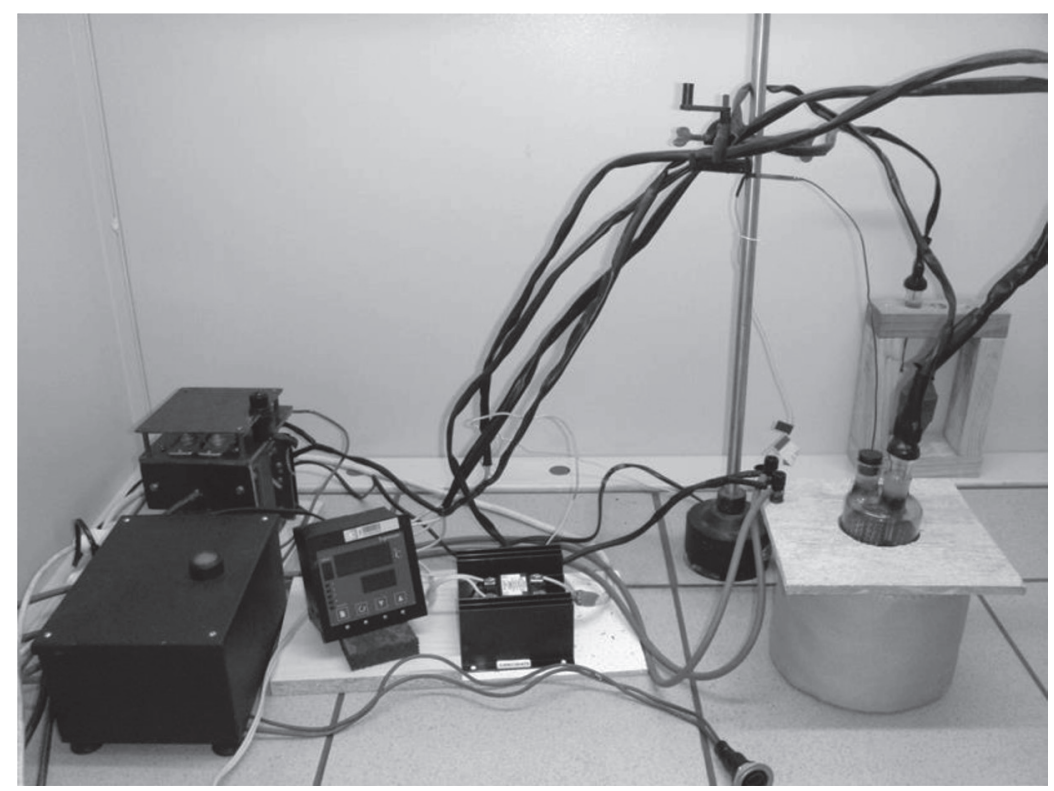

б

Рис. 1. Аппарат по ГОСТ 12.1.044

а-схематический вид тестера без термостата [1]; б-общчий вид прибора в сборе [5]

ления ТПВ на основе таблиц или номограмм, описывающих зависимости $\mathrm{T}=f\left(P_{\text {нас }}\right)$, где $P_{\text {нас }}$ - давление насыщенного пара при НКПВ или ВКПВ [11]. $\mathrm{B}$ начале прошлого века появились первые расчетные методы (Торнтона (Thornton), правило ЛеслиДжениз (Leslie-Geniesse Rule) и другие на основе зависимости $\mathrm{T}=f\left(P_{\text {нас }}\right)$ [12]. Следует отметить, что для большинства ЛВЖ разница между НТПВ и ТВ незначительна ${ }^{1}$ и порой не превышает норми-

\footnotetext{
${ }^{1}$ Исключением являются «медленногорящие» жидкости, например галогеналканы, у которых это различие существенно [12].
}

рованной экспериментальной ошибки определения $\mathrm{TB}$, поэтому такой подход вполне оправдан.

В качестве следствия обеспечения безопасного применения керосина можно отметить стремление нахождения истинной (наименьшей) его температуры вспышки. Для достижения этой цели применяются различные инженерные решения. Одним из которых является увеличение концентрации горючих паров за счет барботажа воздуха через слой жидкости. В 1866 году при испытании российского керосина «Ладога» (“Ladoga”) английским химиком Джоном Эттфилдом (John Attfield) 


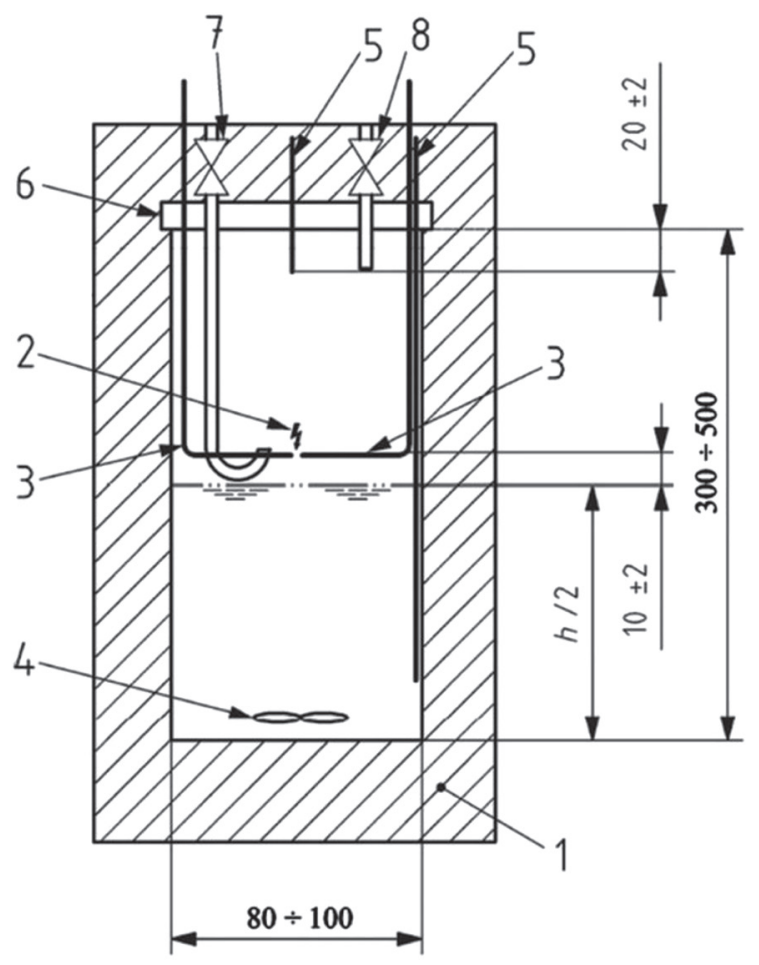

1 - толстостенный стеклянный сосуд, выдерживающий избыточное давление до 10 бар;

2 - искра;

3 - электроды;

4 - мешалка;

5 - термопары для измерения температуры паровой и жидкой фаз;

6 - прокладка;

7 - трубка с краном для продувки воздухом;

$\boldsymbol{8}$ - трубка с краном для сброса избыточного давления

Рис. 2. Прибор по стандарту EN 15794 [6]

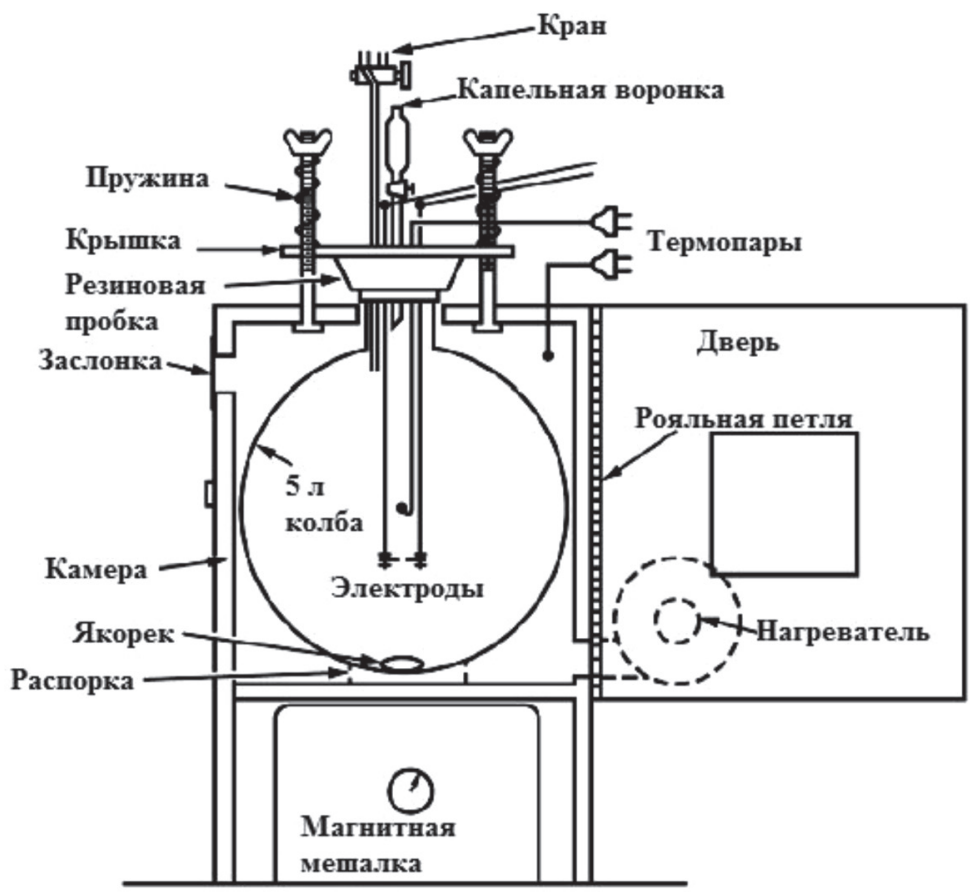

Рис. 3. Аппарат по ASTM E1232-07 [3]

впервые установлено, что данная операция приводит к снижению ТВ [13]. В 80-х годах 19-го столетия разработаны первые открытые паровые аппараты Лио Либэманна (Leo Liebermann), Джона Стоддарда (John T. Stoddard) и Федора Федоровича Бейльштейна для контроля осветительных ма- сел с использованием эффекта, обнаруженного Дж. Эттфилдом [9].

В 1880-90-е годы разработаны различные полузакрытые паровые тестеры [8, 9]. Комбинация конструктивных элементов открытых и полузакрытых паровых аппаратов, как показано ниже, 
Нормативные допуски для методов определения ТПВ [1-3, 6]

\begin{tabular}{|c|c|c|c|}
\hline \multirow{2}{*}{$\begin{array}{c}\text { ЛВЖ/ГЖ, легкоплавкие } \\
\text { вещества и смеси }\end{array}$} & \multicolumn{2}{|c|}{ Допустимые расхождения, ${ }^{\circ} \mathrm{C}$} & \multirow{2}{*}{ Стандарт } \\
\hline & Сходимость & Воспроизводимость & \\
\hline \multirow{4}{*}{$\begin{array}{l}\text { Химические органические } \\
\text { вещества и нефтепродукты }\end{array}$} & 7 & 15 & ГОСТ 12.1.044-89 \\
\hline & 6 & 8 & ГОСТ 12.1.044-2018 \\
\hline & \multirow{2}{*}{\multicolumn{2}{|c|}{ не установлены }} & BS EN 15794:2009 \\
\hline & & & ASTM E1232-07 (2019) \\
\hline \multirow{4}{*}{$\begin{array}{l}\text { Технические смеси } \\
\text { и реакционные массы }\end{array}$} & 9 & 20 & ГОСТ 12.1.044-89 \\
\hline & 9 & 15 & ГОСТ 12.1.044-2018 \\
\hline & \multirow{2}{*}{\multicolumn{2}{|c|}{ не установлены }} & BS EN 15794:2009 \\
\hline & & & ASTM E1232-07 (2019) \\
\hline
\end{tabular}

с успехом применялась в США и Японии для определения ТПВ.

В это же время в Швейцарии к решению данной задачи подошли другим путем - концентрация горючих паров в закрытом пространстве. В результате этого решения на свет появляются закрытые паровые тестеры для определения ТВ [9], которые также можно рассматривать, как прототипы будущих стандартных тестеров для определения ТПВ.

\section{Нестандартные приборы определения ТПВ}

В 1902 году Паулем Этнером (Paul Eitner) для определения КПВ этанола применен полуэмпирический способ исходя из ТПВ. Для этой цели им использована взрывная бюретка. ${ }^{2}$ В результате проведенного исследования установлено, что взрывоопасная область простирается от 13,5 до $34,8{ }^{\circ} \mathrm{C}$ [14]. По современным данным для этанола: НТПВ $=\left(11{ }^{\circ} \mathrm{C}[15,16], 9{ }^{\circ} \mathrm{C}[17]\right)$, ВТПВ $=\left(41{ }^{\circ} \mathrm{C}[15], 44^{\circ} \mathrm{C}\right.$ [17], $42{ }^{\circ} \mathrm{C}$ [16]). Таким образом, с учетом допустимой нормативной ошибкой (табл. 1) данный результат можно считать вполне удовлетворительным.

Следующей попыткой определения ТПВ можно считать нахождение температурной области взрыва паров керосина для двух марок керосина. Для этой цели С.П. Брэдли (S.P. Bradley) и К.Ф. Хэйлом (C.F. Hale) предложен аппарат, состоящий из 0,56 литрового латунного взрывного цилиндра $\mathbf{1}$, оснащенного гильзой для термометра 2 , барботером 3 с запорным краном для сухого воздуха, искрового источника зажигания (ИЗ) 4 , газоотводной трубки 5 с запорным краном и манометром 6 (рис. 4a). Процедура испытаний состоит из медленного нагрева прибора с пробой керосина ( 390 мл)

2 В работе [14] не дано детальное описание взрывной бюретки. на водяной бане, перед тестированием на вспышку осуществляют кратковременный барботаж воздуха при открытых запорных кранах, после чего их перекрывают и дают искровой разряд. Явление вспышки (взрыва) фиксируют с помощью манометра. Авторами данного исследования установлено, что температурная область взрыва паров керосина выходит за границы отрезка, ограниченного температурой вспышки в полузакрытом тестере Артура Эллиотта (Arthur H. Elliott) и температурой воспламенения в открытом аппарате Джона Тальябу (John Tagliabue) $)^{3}$ [18].

Сравнительный анализ результатов этой работы [18] с современными данными по пожарной опасности керосинов [20] показывает, что прибор Брэдли-Хэйла может использоваться только для оценочного определения ТПВ.

В 1923 году Эдвардом Маком (Edward Mack) с коллегами на основе комбинации принципов действия открытых и полузакрытых паровых аппаратов для определения ТВ предложен прибор, приведенный на рисунке 4б. Данный прибор состоит из реакционного тигля пробирочного типа $\mathbf{1}$, оснащенного искровым ИЗ 2 , термометром $\mathbf{3}$, барботером для сухого воздуха 4 и газоотводной трубкой 5. Для обеспечения равномерности нагрева установка помещена в стеклянный сосуд Дьюapa (Dewar flask). Для проведения экспериментов при температуре ниже комнатной температуры используется охлаждающая смесь (ацетон+сухой лед), а для определения температуры вспышки выше комнатной температуры применяется горячая вода. ${ }^{4}$ НТПВ определены 37 индивидуальных

\footnotetext{
3 Тестеры Артура Эллиотта и Джона Тальябу рассмотрены в работах $[7,8]$.

${ }^{4}$ В работе не отмечается, как определен НТПВ бензойной кислоты, очевидно вместо водяной использована масляная баня.
} 


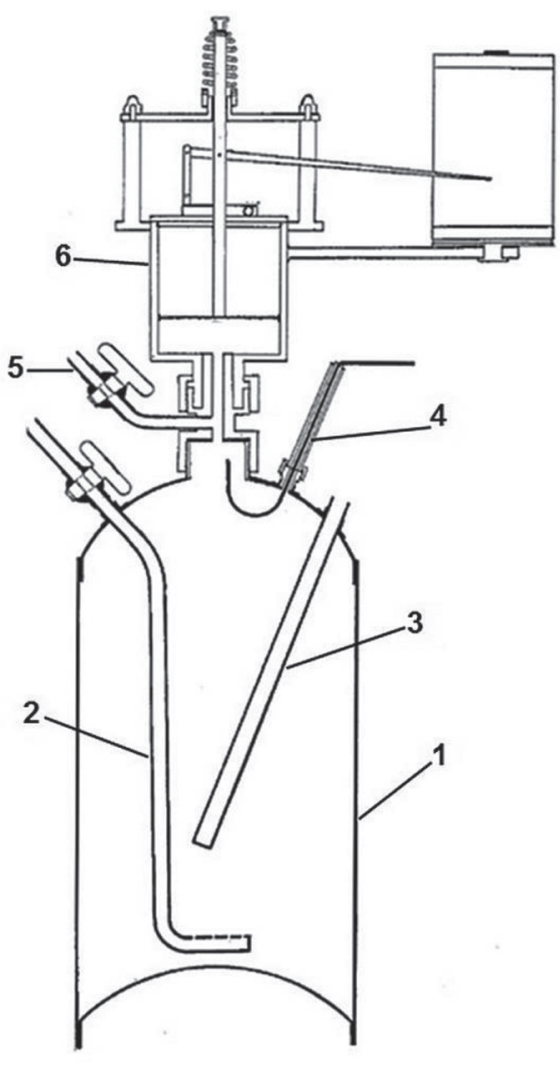

a

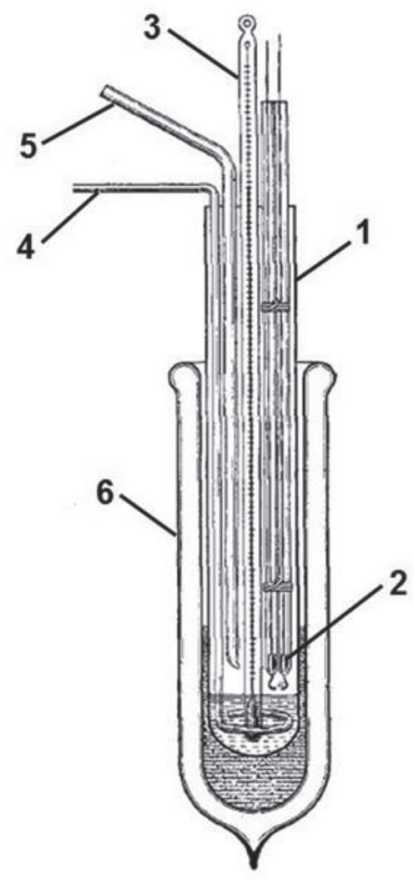

б

Рис. 4. Первые аппараты для определения ТПВ

a- аппарат Брэдли-Хэйла [9, 18], б- прибор Мака [9, 19]

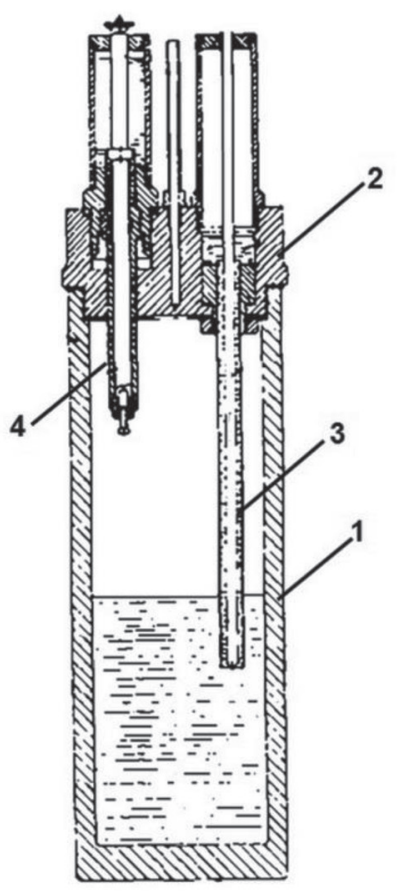

a
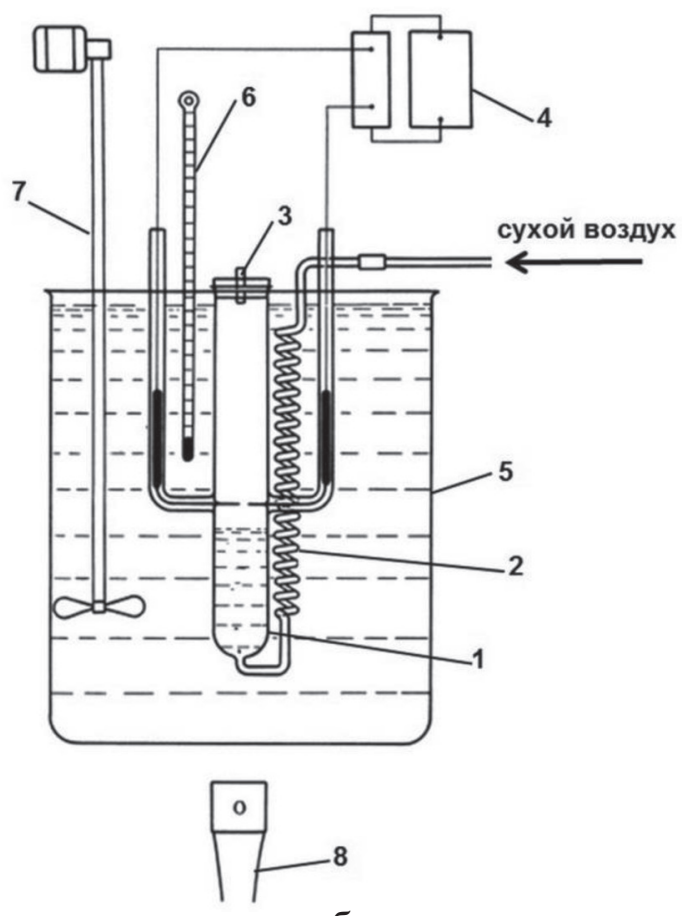

6

Рис. 5. Аппараты для определения ТПВ

a-автоклав Фрике [21]; б - прибор Джонса [22] 
ЛВЖ/ГЖ различных классов органических соединений (алканы, арены, сложные эфиры, фенолы, спирты), а также нитробензола, бензойной кислоты и сероуглерода [19]. Сопоставление результатов работы Э. Мака с коллегами [19] и современных данных по значениям НТПВ органических соединений $[15-17,20]$ демонстрирует, что прибор, приведенный на рисунке $1 б$ (табл. 1), может быть использован для определения с приемлемой точностью НТПВ большинства ЛВЖ/ГЖ, исключение составляют только гексан $\left(\Delta \mathrm{t}=\right.$ (минус) $8 \div 10{ }^{\circ} \mathrm{C}$ $[17,16,20])$, кумол $\left(\Delta t=21 \div 23^{\circ} \mathrm{C}[17,16,20]\right)$ и сероуглерод $\left(\Delta \mathrm{t}=\right.$ (минус) $\left.25^{\circ} \mathrm{C}[15]\right)$.

В 1933 году К. Фрике (K. Fricke) для определения ТПВ этанола и его водных растворов использован стальной автоклав, состоящий из стального корпуса 1 с крышкой 2 , оснащенного термопарой $\mathbf{3}$, электрическим ИЗ 4, предохранительным клапаном и переходником для присоединения манометра для измерения избыточного давления взрыва (вспышки, рис. 5a) [21]. Найденные К. Фрике значения НТПВ $\left(10,6{ }^{\circ} \mathrm{C}\right)$ и ВТПВ $\left(41,2{ }^{\circ} \mathrm{C}\right)$ для этанола [21] хорошо согласуются с современными данными $\left(\Delta \mathrm{t}_{\text {Нтпв }}=0,4 \div 1,4{ }^{\circ} \mathrm{C}[15-17], \Delta \mathrm{t}_{\text {втпв }}=0,2 \div 2,8^{\circ} \mathrm{C}\right.$ $[15-17])$.

В 40-50-е годы прошлого столетия американским горным бюро (US Bureau of mines) проведен цикл исследований по определения ТПВ ряда органических жидкостей с помощью прибора Джорджа В. Джонса (George W. Jones) [22-28], который paнее использовался для экспериментального нахож- дения концентрационных пределов воспламенения (КПВ) [29]. Данный аппарат состоит из взрывного стеклянного цилиндра ( $\mathbf{1}$, оснащенного трубкой со змеевиком для барботажа воздуха 2, корковая пробка с небольшим отверстием $\mathbf{3}$ и системой для электрического поджигания паров 4. Данный прибор помещен в термостат 5, оборудованный электрической мешалкой 7, термометром 6 и газовой горелкой 8 (рис. 5б). При тестировании через пробу ЛВЖ/ГЖ пропускается сухой воздух со скоростью 5 пузырьков в секунду. Перед тестом на вспышку взрывной цилиндр с испытуемой пробой выдерживается 20 минут при каждой температуре для создания условий для образования насыщенного пара. В результате исследований американского горного бюро определены ТПВ акрилонитрила, амилнитрита, нафталина, стирола, трихлорэтилена и уксусного ангидрида [22-28], значения, которых хорошо согласуются с данными полученными по методам ГОСТ 12.1.044, EN 13237 и ASTM E1232 [15-17, 20].

Интересно отметить, что в 1952 году американским горным бюро для определения ТПВ авиационных топлив для реактивной авиации вместо прибора Джонса было использовано другое инженерное решение - помещение своего прибора для экспериментального нахождения КПВ в термостат (рис. 6) [30]. В устройстве генератора паровоздушной смеси (рис. 7) задействован принцип действия открытых паровых тестеров для определения температуры вспышки [9]. Аналогич-

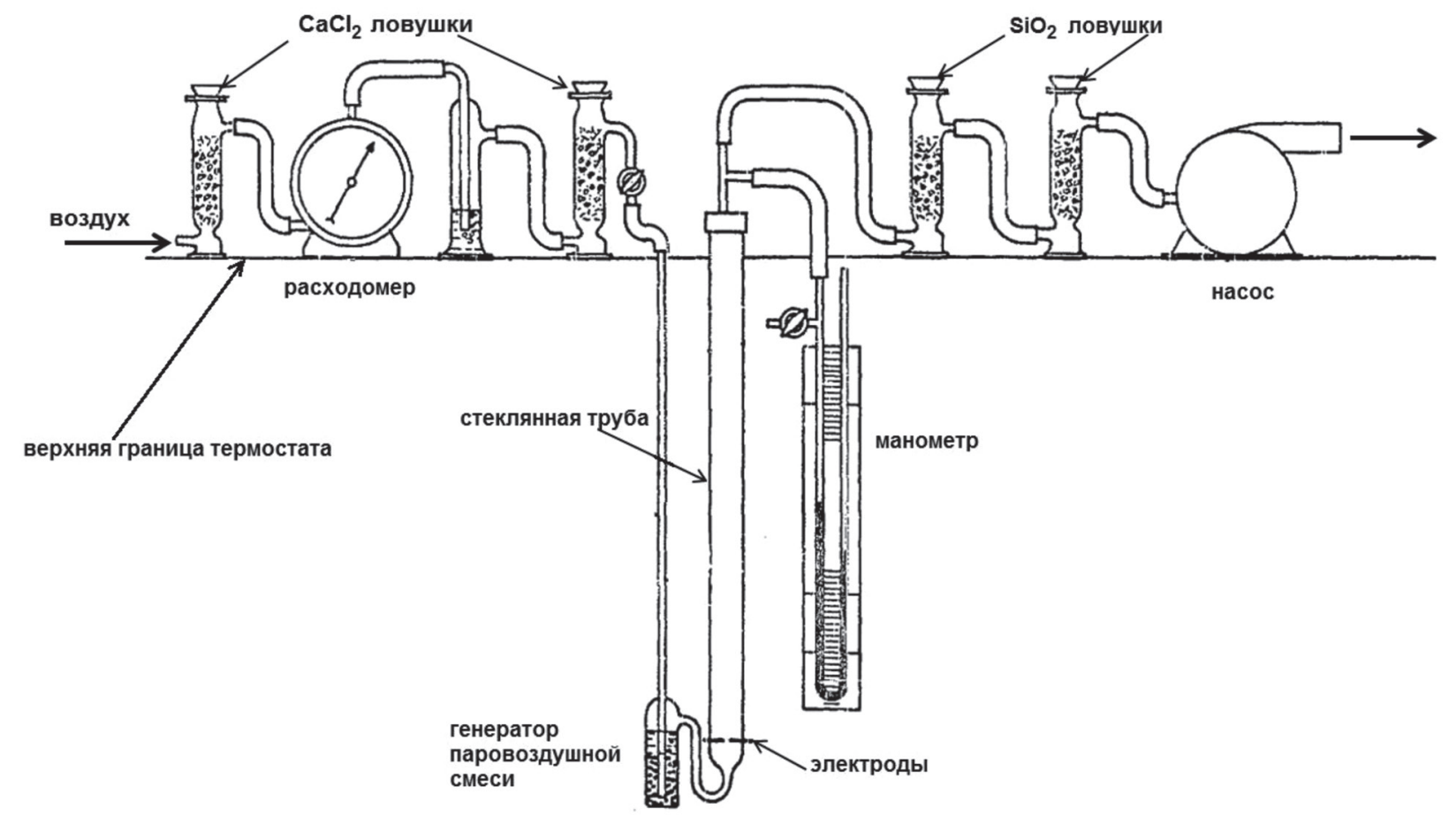

Рис. 6. Метод американского горного бюро [30] 


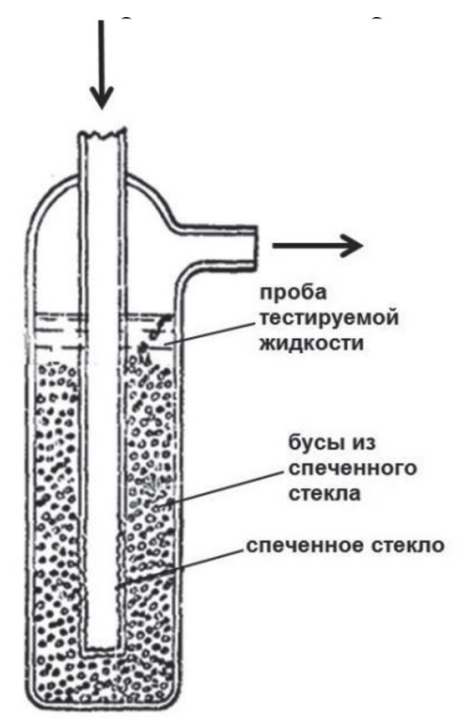

Рис. 7. Устройство генератора паровоздушной смеси [30]

ный подход для решения подобной задачи был применен исследовательской лабораторией ВМФ США (Naval Research Laboratory of Department of the Navy of US), но вместо громоздкого прибора американского горного бюро в термостат помещен миниприбор (рис. 8а) [31], который является модификацией аппарата (рис. 8б), ранее используемого для изучения влияния температуры на КПВ [32].

В 1985 году японским исследователем С. Ягуи (S. Yagyu) предложены несколько модификаций прибора Джонса для различных ЛВЖ/ГЖ (рис. 9а,б и 10а,б) [33, 35], на которых им с высокой точностью определены ТПВ для 111 индивидуальных органических ЛВЖ/ГЖ [36-45].

На Международной конференции по топливам и смазочным материалам, которая проходила в октябре 1985 года в городе Талса штата Оклахома, представлена цилиндрическая стеклянная бомба для определения ТПВ топлив (рис. 11) [46].

В 50-е годы в Центральном научно-исследовательском институте пожарной обороны (в настоящее время Всероссийский НИИ пожарной обороны МЧС России) был разработан стальной аппарат ТП для определения ТПВ (рис. 12) [47-49]. В дальнейшем было установлено, что в стальном аппарате несколько завышаются значения ТПВ по сравнению со стеклянным аппаратом $[48,50]$, поэтому в 1968 году метод определения ТПВ и стеклянный аналог прибора ТП (рис. 1) был в ГОСТ 13922$68[51,52]$. В последующем данный прибор и метод определения ТПВ перешел в ГОСТ 12.1.022-80 [53], а затем в ГОСТ 12.1.044 (1984, 1989 и 2018 годов) $[1,2,54]$.

В 50-60-е годы в отечественной технической литературе появились понятия «низший и высший пределы температуры вспышки», но при этом они не рассматривались как синонимы НТПВ и ВТПВ. Под низшим пределом температуры вспышки понимается сама температура вспышки, определенная в закрытом аппарате Абеля (Abel), или Абеля-Пенского (Abel-Pensky), или ПенскиМартенса (Pensky-Martens), а под высшим пределом температуры вспышки - максимальная температура ЛВЖ/ГЖ при которой еще наблюдается

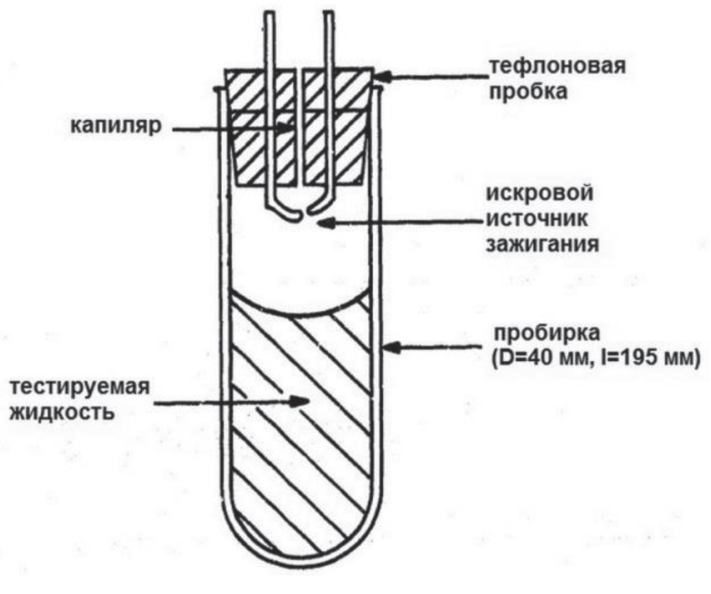

a

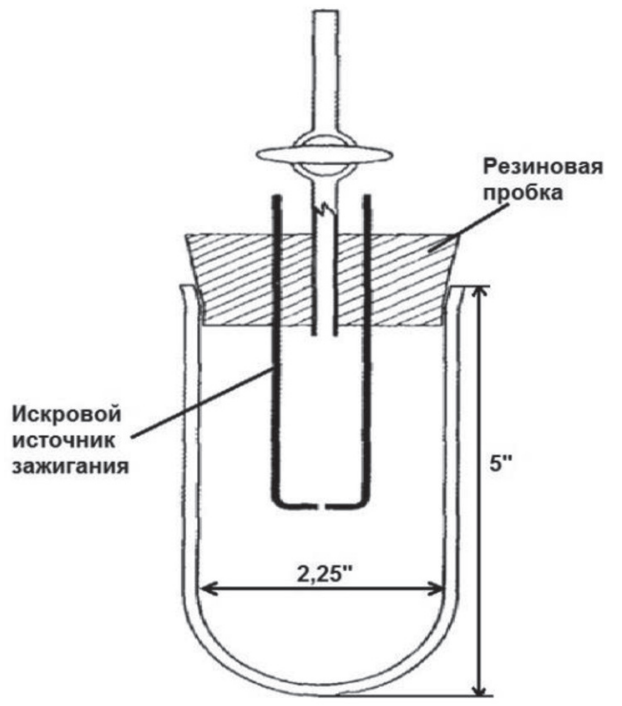

б

Рис. 8. Миниприборы

a- аппарат военно-морской исследовательской лабораторией ВМФ США,

б-тестер Боллса-Либхефского (Balls-Liebhefsky) [32] 


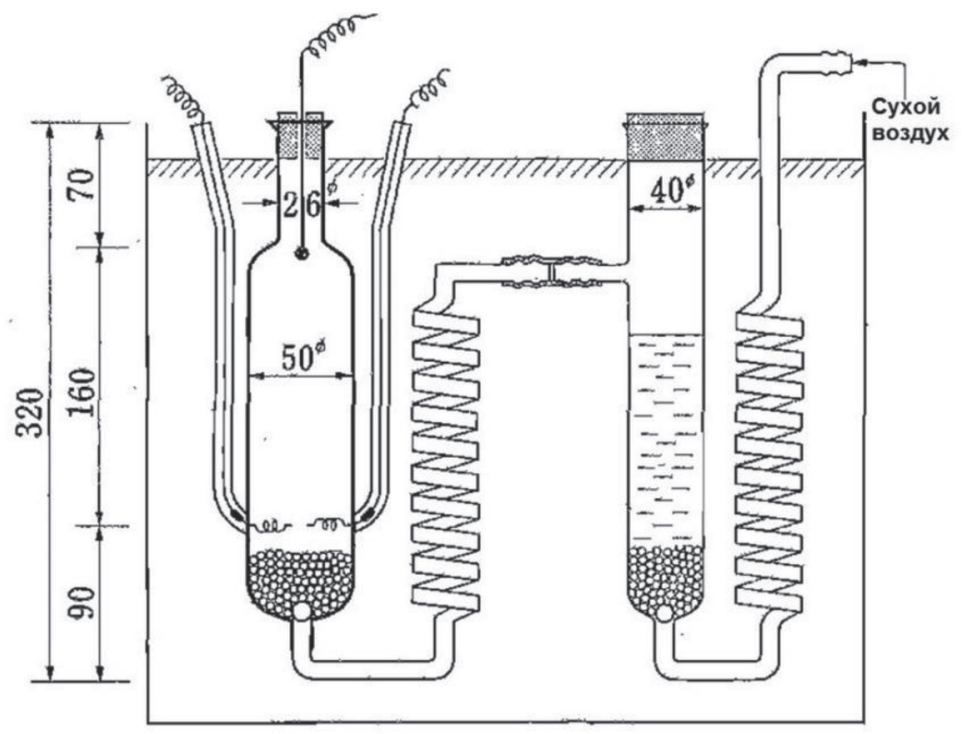

a

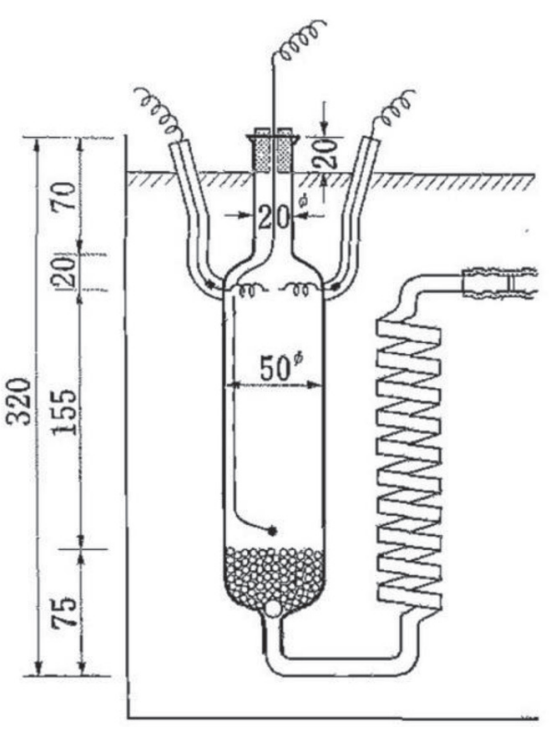

$\sigma$

Рис. 9. Динамические японские модификации прибора Джонса [33]

$a$ - для высококипящих жидкостей; б - для низкокипящих жидкостей

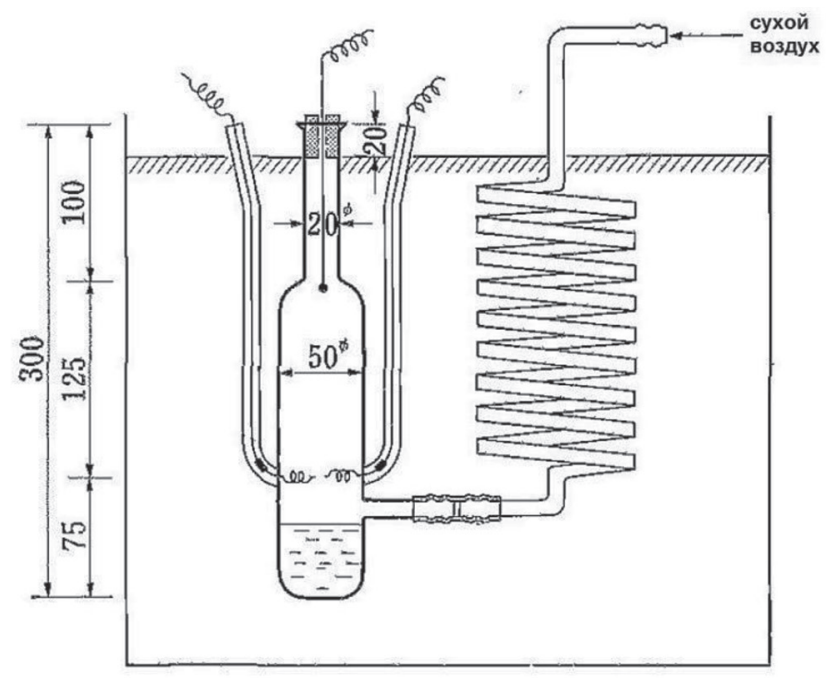

a

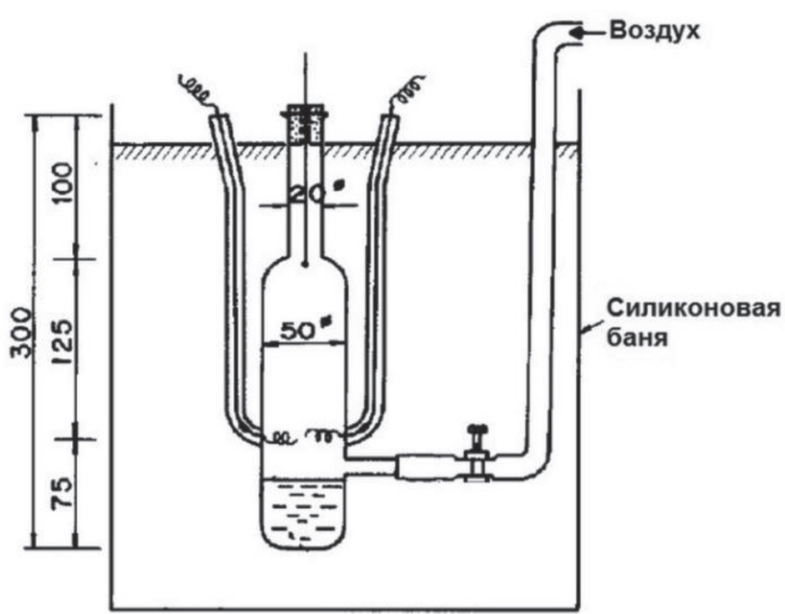

б

Рис. 10. Статические японские модификации прибора Джонса

a - вариант для особо опасных ЛВЖ [33]; б - вариант для измерения ВТПВ [34, 35]

вспышка в одном из вышеперечисленных закрытых тестеров [55, 56]. Из сравнения данных, представленных в таблице 2, видно, что верхний предел температуры вспышки хорошо согласуется с ВТПВ. Это означает, что обычные аппараты типа закрытый тигель при небольшой модификации стандартной методики испытаний потенциально могут быть использованы для определения ВТПВ.

В 1990 году японские исследователи К. Хасегава (К. Hasegawa) и К. Кашики (K. Kashiki) модифицировали закрытый прибор сета-флэш (seta-flash) для измерения ВТПВ (верхней температуры вспышки) для индивидуальных ЛВЖ/ ГЖ и их смесей (рис. 13) [34, 35, 57]. В большинстве случаев результаты испытаний хорошо согласуются с литературными данными $[15-17,20]$, но для некоторых органических жидкостей абсолютная ошибка $\left(\Delta \mathrm{t}_{\text {втпв }}\right)$ выходит за рамки нормативной погрешности (табл. 1). Так, $\Delta \mathrm{t}_{\text {втпв }}$ для уксусной кислоты, 


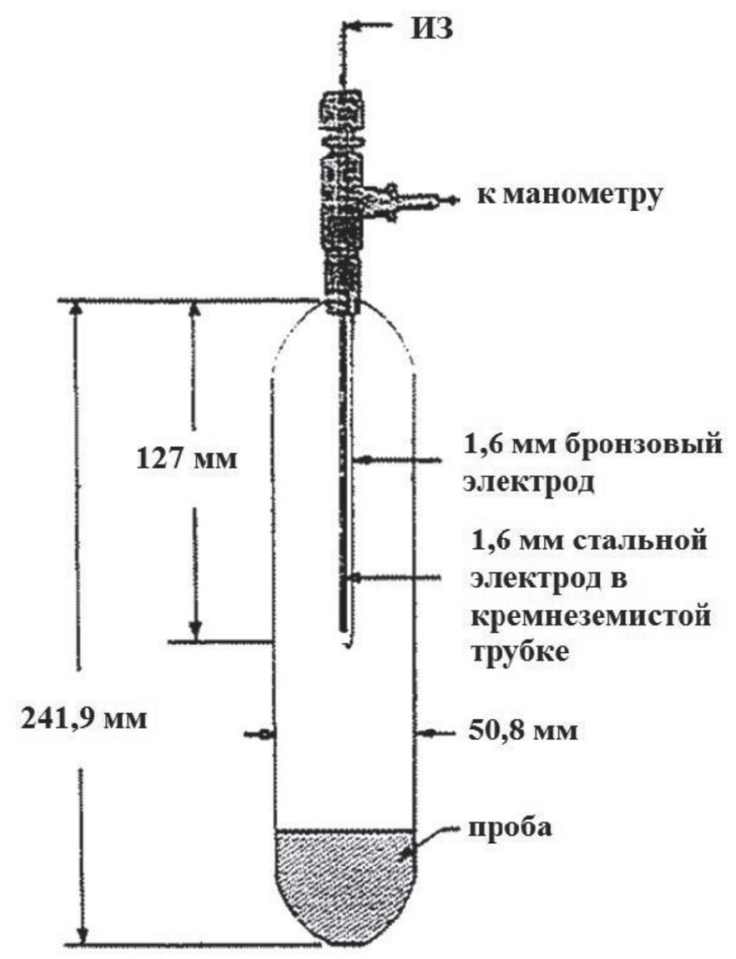

Рис. 11. Цилиндрическая бомба Д. Дж. Гордона (D. J. Gordon) с сотр. для определения ТПВ [46]

диоксана, толуола, диэтилового эфира, ${ }^{5}$ и винилацетата равна $(17 \div 21),(12 \div 14), 16,5,(10 \div 11)$ и $11{ }^{\circ} \mathrm{C}$ соответственно.

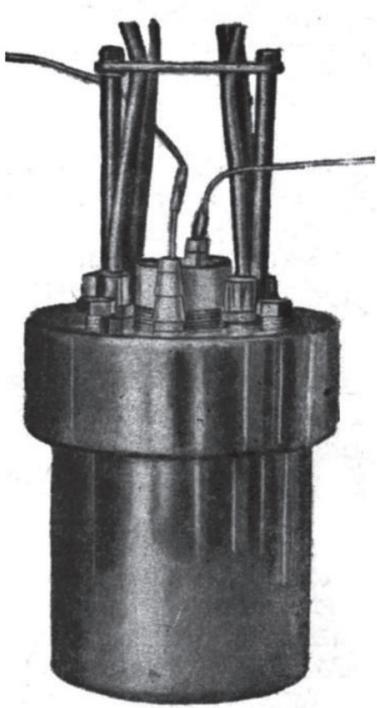

a

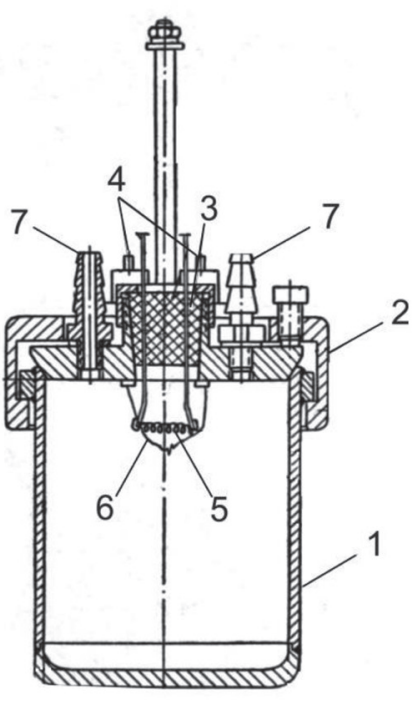

б

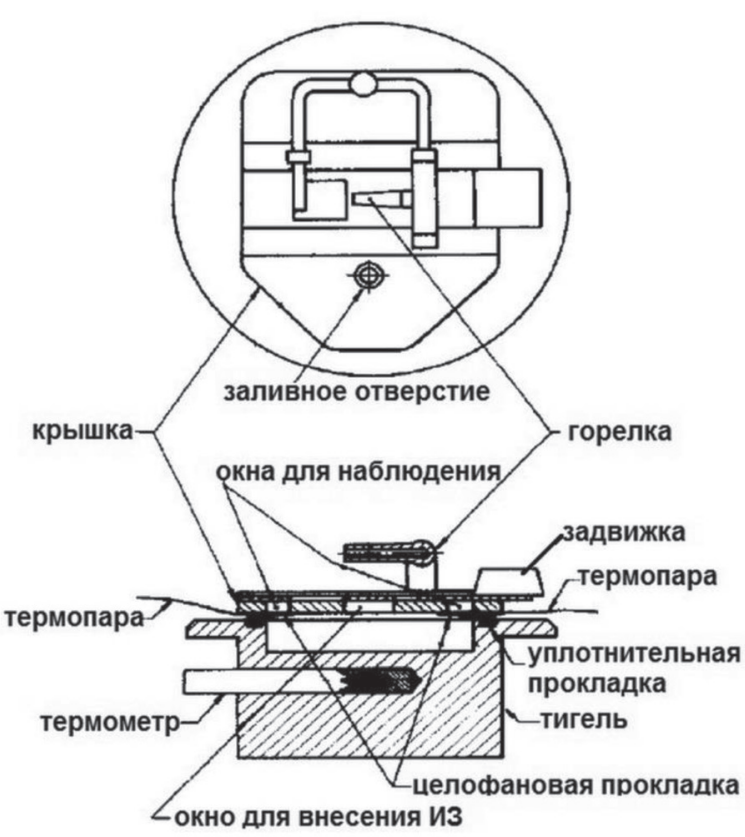

Рис. 13. Модифицированный закрытый сета-флэш тестер $[34,35]$

В 2003 году американскими и британскими исследователями для определения НТПВ ${ }^{6}$ ряда ЛВЖ в воздушной среде и атмосфере кислорода применен стальной автоклав диаметром 67 мм и высотой 122 мм (рис. 14a), помещенный в жидкост-

\footnotetext{
1 - сосуд для испытуемой жидкости;

2 - крышка;

3 - каучуковая пробка;

4 - штуцеры для ввода термопар;

5 - спираль накаливания;

6- термопара;

7 - штуцер для выравнивания давления
}

Рис. 12. Прибор ТП для определения ТПВ

$a$-внешний вид; б-разрез [47]

\footnotetext{
${ }_{5}^{5}$ В случае эфиров наблюдаемая абсолютная ошибка, возможно, связана с наличием в них перекисных соединений. В работах $[34,35]$ нет указаний, что перед тестированием авторами осуществлена очистка эфиров от перекисей.
}

ную баню в холодильнике-нагревателе с автоматическим контролем температуры [58]. Найденные

\footnotetext{
${ }^{6}$ В работе [58] НТПВ трактуется, как температура вспышки.
} 
Сравнение верхнего предела температуры вспышки и ВТПВ

\begin{tabular}{lcc}
\hline \multicolumn{1}{c}{ ЛВж } & Верхний предел температуры вспышки, ${ }^{\circ} \mathbf{C}$ & ВТПВ, ${ }^{\circ} \mathbf{C}$ \\
\hline Этанол & 41 & $41^{2}, 44^{3}, 42^{4}$ \\
Бутанол & 61 & $67^{1,4}$ \\
Ацетон & 7,5 & $61,7^{4}$ \\
\hline
\end{tabular}

Примечания. ${ }^{1-4}$ Справочные данные: [20], [15], [17], [16] соответственно.

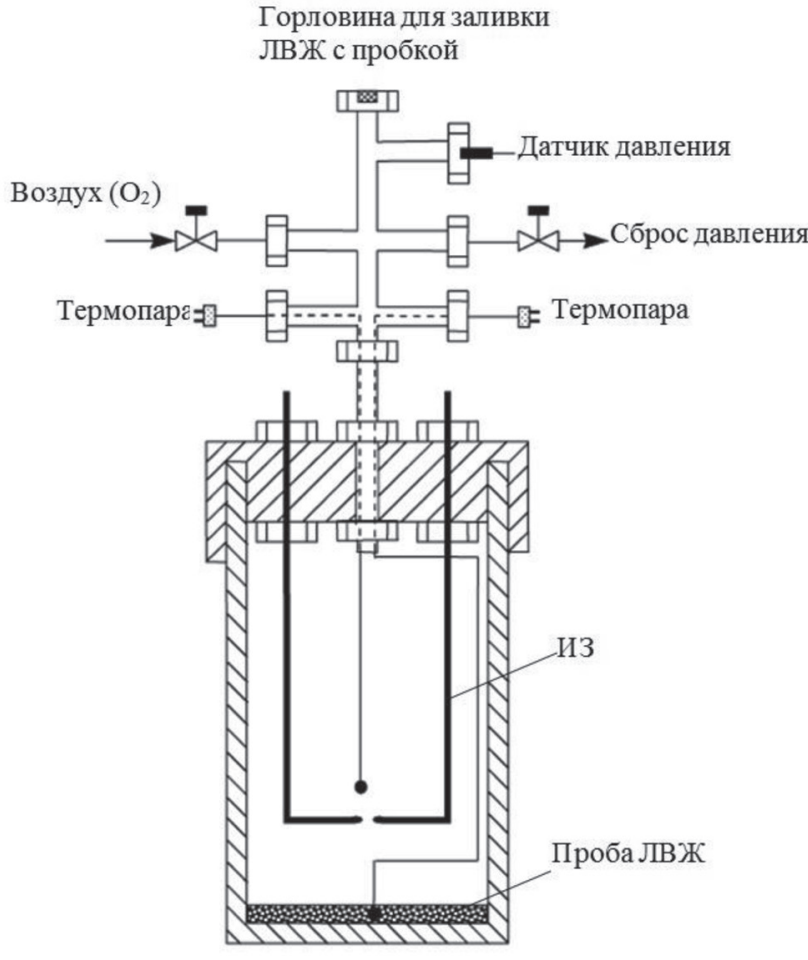

a

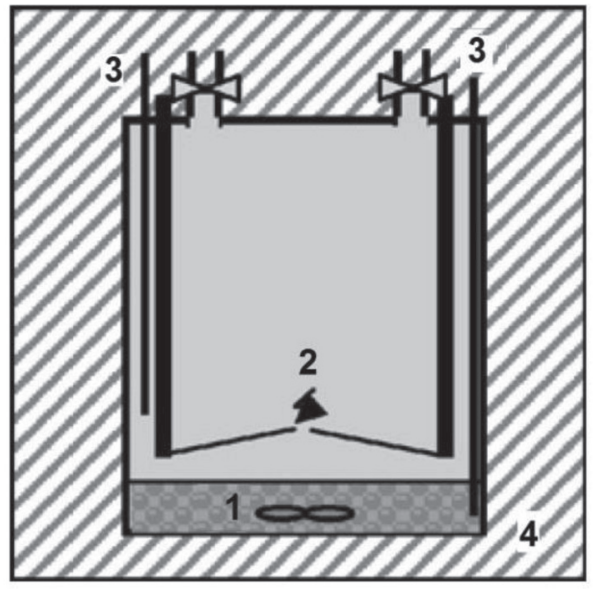

1 - мешалка;

2-ИЗ;

3 - термопара;

4 - термостат

Рис. 14. Автоклавы для определения НТПВ

$a$-американский аппарат [58]; б-европейский прибор [59]

значения НТПВ хорошо согласуются с литературными данными [15-17, 20].

В 2007 году Элизабет Брандес (Elisabeth Brandes) с коллегами предложен прототип европейского прибора для определения ТПВ (рис. 2), который представляет стеклянный сосуд диаметром 150 мм и высотой 200 мм, оснащенный ИЗ, который используется для определения КПВ по стандарту EN 1839 [60], а также мешалкой и термопарами для контроля жидкой и паровой фаз (рис. 14б). Данный прибор апробирован на ряде индивидуальных ЛВЖ и их смесей [59].

Лоран Дюпоном (Laurent Dupont) для определения ТПВ водных растворов аммиака использован 20 л сферическая стальная бомба (рис. 15) [61], которая часто используются для нахожде- ния КПВ и минимального содержания кислорода при повышенном (пониженном) давлении и температуре $[1,2,60,62,63]$. Как видно из таблицы 3 полученные в работе [61] результаты в пределах нормативной допуска согласуются с литературными данными [20].

Подобная 5 литровая сферическая бомба также использована для определения НТПВ октанола и этанола при пониженных и повышенных давлениях [64].

\section{Заключение}

ТПВ являются одними из важных показателей пожаровзрывоопасности, которые используются при разработке мероприятий по обеспече- 
ТПВ водных растворов аммиака

\begin{tabular}{ccc}
\hline \multirow{2}{*}{ Концентрация $\mathrm{NH}_{3}, \%$} & {$[61]$} & ТПВ, ${ }^{\circ} \mathrm{C}$ \\
\cline { 2 - 3 } & $24,0 \div 37,5$ & $23 \div 33$ \\
\hline 15 & $0,1 \div 17,0$ & $-2 \div 10^{1}$ \\
\hline
\end{tabular}

Примечание. ${ }^{1}$ Для 27 \% аммиачного раствора.

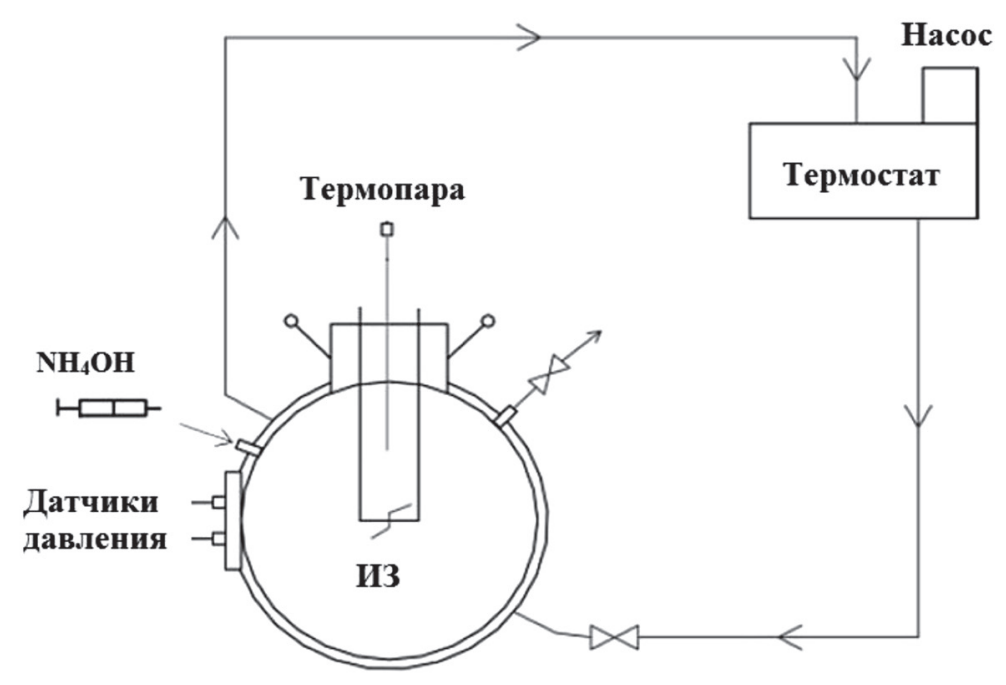

Рис. 15. 20 л сферическая стальная бомба для определения ТПВ $\mathrm{NH}_{4} \mathrm{OH}$ [61]

нию пожаровзрывобезопасности производственных объектов, применяются при расчете температурных режимов для хранения, транспортировки и переработки ЛВЖ и ГЖ. Однако по сравнению с температурой вспышкой и КПВ экспериментальных данных по ТПВ не много. В настоящей работе показано, что наряду со стандартными приборами и методами определения ТПВ существует большой ряд нестандартных тестеров, доступных широкому кругу пользователей и с помощью которых можно определять ТПВ с приемлемой точностью.

\section{Литература}

1. ГОСТ 12.1.044-89. ССБТ. Пожаровзрывоопасность веществ и материалов. Номенклатура показателей и методы их определения. Москва: Стандартинформ. 2006. 99 c.

2. ГОСТ 12.1.044-2018. ССБТ. Пожаровзрывоопасность веществ и материалов. Номенклатура показателей и методы их определения. Москва: Стандартинформ. 2018. 206 с.

3. ASTM E1232-07 (2019). Standard test method for temperature limit of flammability of chemicals. West Conshohocken: ASTM International, 2019. 11 p.
4. BS EN 13237:2012. Potentially explosive atmospheres - Terms and definitions for equipment and protective systems intended for use in potentially explosive atmospheres. London: BSI, 2010. 22 p.

5. Алексеев К.С. Дис. ... канд. техн. наук. Уфа, 2016. $155 \mathrm{c}$.

6. BS EN 15794:2009. Determination of explosion points of flammable liquids. London: BSI, 2012. 32 p.

7. Алексеев С.Г., Смирнов В.В., Барбин Н.М. Российский химический журнал. 2018. Т. 62. №3. С. 71-87.

8. Алексеев С.Г., Смирнов В.В., Барбин Н.М. Российский химический журнал. 2019. Т. 63. № 1. С. 55-70. DOI: $10.6060 /$ rcj.2019631.4.

9. Алексеев С.Г., Смирнов В.В., Зарипова К.А., Барбин H.M. Российский химический журнал. 2019. Т. 63. № 1. C. 71-85. DOI: 10.6060/rcj.2019631.5.

10. Алексеев С.Г., Смирнов В.В., Алексеев К.С., Барбин H.M. Российский химический журнал. 2019. Т. 63. №2. C. 85-97. DOI: 10.6060/rcj.2019632.12.

11. Physikalisch-Chemische Tabellen. Heraugegeben von H. Landolt, R. Börnstein. Berlin: Verlag von Julius Springer, 1894. $582 \mathrm{~s}$.

12. Алексеев С.Г., Смирнов В.В., Барбин Н.М. Пожаровзрывобезопасность. 2012. Т. 21. №10. С. 21-35.

13. Attfield J. Pharmaceutical Journal and Transactions. Second Series. 1866. V. 8. No 6. P. 318325. 
14. Eitner P. Journal für Gasbeleuchtung und Wasserversorgung. 1902. Jahr. 45. S. 112-115.

15. Корольченко А.Я., Корольченко Д.А. Пожаровзрывобезопасность веществ и материалов и средства их тушения. Справочник. Москва: Пожнаука, 2004. Ч. $2.774 \mathrm{c}$.

16. DIPPR 801. Режим доступа: https://dippr.aiche.org/.

17. GESTIS Substance Database. Режим доступа: https:// gestis-database.dguv.de/.

18. Bradley W.P., Hale C.F. The Journal of Industrial \& Engineering Chemistry. 1909. V. 1. No 6. P. 345. DOI: 10.1021/ie50006a006.

19. Mack E., Boord C.E., Barham H.N. Industrial \& Engineering Chemistry. 1923. V. 15. No 9. P. 963-965. DOI: 10.1021/ie50165a046.

20. Корольченко А.Я., Корольченко Д.А. Пожаровзрывобезопасность веществ и материалов и средства их тушения. Справочник. Москва: Пожнаука, 2004. Ч. $1.713 \mathrm{c}$.

21. Fricke K. Angewandte Chemie. 1933. Bd 46. Nr 5. S. 87-90. DOI: 10.1002/ange.19330460503.

22. Jones G.W., Kennedy R.E., Scott G.S. Report of Investigation No 3597. Washington: Bureau of Mines, 1941. 9 p.

23. Jones G.W., Scott G.S. Report of Investigation 3666. Washington: Bureau of Mines, 1942. 7 p.

24. Jones G.W., Scott G.S., Miller W.E. Report of Investigation No 3630. Washington: Bureau of Mines, 1942. 9 p.

25. Jones G.W., Kennedy R.E., Scott G.S. Report of Investigation No 3727. Washington: Bureau of Mines, 1943. $12 \mathrm{p}$.

26. Jones G.W., Scott F.E., Scott G.S. Report of Investigation No 3741. Washington: Bureau of Mines, 1943. 8 p.

27. Jones G.W., Scott G.S. Report of Investigation No 3881. Washington: Bureau of Mines, 1946. 7 p.

28. Zabetakis M.G., Jones G.W. Report of Investigation No 4877. Washington: Bureau of Mines, 1952. 7 p.

29. Jones, G. W. Chemical Reviews. 1938. V. 22. No 1. P. 1-26. DOI:10.1021/cr60071a001.

30. Jones G.W., Zabetakis M.G., Richmond J.K., Scott G.S., Furno A.L. WADC Technical Report No 52-53. Wright-Patterson Air Force Base: Wright Air Development Center, 1952. 104 p.

31. Affens W.A., Carhart H.W. NRL Memorandum Report No 1735. Washington: Naval Research Laboratory, 1966. $12 \mathrm{p}$.

32. Balls E.W., Liebhefsky H.A. Industrial \& Engineering Chemistry. 1946. V. 38. No 6. P. 583-585. DOI:10.1021/ ie $50438 \mathrm{a} 014$.

33. Yagyu S. Journal of Japan Society for Safety Enginennring. 1985. V. 24. No 3. P. 152-158. DOI: 10.18943/ safety.24.3_152.

34. Hasegawa K., Kashiki K. Journal of Japan Society for Safety Enginennring. 1990. V. 29. No 5. P. 332-340. DOI: $10.18943 /$ safety.29.5_332.

35. Hasegawa, K., Kashiki, K. Journal of Loss Prevention in the Process Industries. 1991. V. 4. No 3. P. 176-184. DOI:10.1016/0950-4230(91)80034-r.

36. Yagyu S. Journal of Japan Society for Safety Enginennring. 1985. V. 24. No 4. P. 210-215. DOI: 10.18943/ safety.24.4_210.
37. Yagyu S. Journal of Japan Society for Safety Enginennring. 1985. V. 24. No 5. P. 271-276. DOI: 10.18943/ safety.24.5 271 .

38. Yagyu S. Journal of Japan Society for Safety Enginennring. 1986. V. 25. No 1. P. 49-54. DOI: 10.18943/ safety.25.1_49.

39. Yagyu S. Journal of Japan Society for Safety Enginennring. 1986. V. 25. No 2. P. 100-105. DOI: 10.18943/ safety.25.2_100.

40. Yagyu $S$. Journal of Japan Society for Safety Enginennring. 1986. V. 25. No 3. P. 165-170. DOI: 10.18943/ safety.25.3_165.

41. Yagyu S. Journal of Japan Society for Safety Enginennring. 1986. V. 25. No 4. P. 220-225. DOI: 10.18943/ safety.25.4_220.

42. Yagyu $S$. Journal of Japan Society for Safety Enginennring. 1986. V. 25. No 5. P. 277-282. DOI: 10.18943/ safety.25.5_277.

43. Yagyu S. Journal of Japan Society for Safety Enginennring. 1987. V. 26. No 2. P. 110-115. DOI: 10.18943/ safety.26.2_110.

44. Yagyu $S$. Journal of Japan Society for Safety Enginennring. 1987. V. 26. No 3. P. 166-171. DOI: 10.18943/ safety.26.3 166.

45. Yagyu $S$. Journal of Japan Society for Safety Enginennring. 1987. V. 26. No 4. P. 234-240. DOI: 10.18943/ safety.26.4_234.

46. Gordon D.J., Murin J., Cruice W. SAE Transactions. 1985. V. 94. P. 712-718. DOI:10.4271/852107.

47. Годжелло М.Г., Демидов П.Г., Джалалов Е.М., Кориак Э.В., Рябов И.В. Легковоспламеняющиеся и горючие жидкости. Справочник. Москва: изд-во Министерства коммунального хозяйства РСФСР, 1956. 112 с.

48. Баратов А.Н., Годжелло М.Г. Пожарная опасность производств, применяющие газы и жидкости. Москва: изд-во Министерства коммунального хозяйства РСФСР, 1961. 84 с.

49. Демидов П.Г. Горение и свойства горючих веществ. Москва: изд-во Министерства коммунального хозяйства РСФСР, 1962. 264 с.

50. Пожарная опасность веществ и материалов, применяемых в химической промышленности. Справочник. Под ред. И.В. Рябова. - Москва: Химия, 1970. $336 \mathrm{c}$.

51. Демидов П.Г., Саушев В.С. Горение и свойства горючих веществ. Москва: ВИПТШ МВД СССР, 1975. $280 \mathrm{c}$.

52. Монахов В.T. Методы исследования пожарной опасности веществ. Москва: Химия, 1979. 424 с.

53. Система стандартов безопасности труда. Москва: изд-во стандартов, 1983. Ч. 2. С. 3-8.

54. ГОСТ 12.1.044-84 (СТ СЭВ 4831-84). ССБТ. Пожаровзрывоопасность веществ и материалов. Номенклатура показателей и методы их определения. Москва: ГК СССР по стандартам. 1987. 138 с.

55. Блинов В.И., Худяков Г.Н. Диффузионное горение жидкостей. Москва: изд-во АН СССР, 1961. 208 с.

56. Демидов П.Г. Основы горения веществ. Москва: изд-во Министерства коммунального хозяйства РСФСР, 1951. 296 c. 
57. Iwata Y., Koseki H., Hasegawa K. Journal of Fire Sciences. 1999. V. 17. No 6. P. 459-476. DOI: 10.1177/073490419901700604.

58. Kong D., am Ende D.J., Brenek S.J., Weston N.P. Journal of Hazardous Materials. 2003. V. 102. No 2-3. P. 155-165. DOI: 10.1016/S0304-3894(03)00212-7.

59. Brandes E., Mitu M., Pawel D. Journal of Loss Prevention in the Process Industries. 2007. V. 20. No 4-6. P. 536-540. DOI:10.1016/j.jlp.2007.04.028.

60. BS EN 1839:2017. Determination of the explosion limits and the limiting oxygen concentration (LOC) for flammable gases and vapours. London: BSI, 2017. 48 p.
61. Dupont L. Process Safety Progress. 2009. V. 28. No 1. P. 36-44. doi:10.1002/prs.10291.

62. Chang Y.-M., Tseng J.-M., Shu C.-M., Hu K.-H. Korean Journal of Chemical Engineering. 2005. V. 22. No 6. P. 803-812. DOI: 10.1007/BF02705658.

63. Lin M.L., Lin N.K., Chen C.C., Liaw H.J., Shu C.M. Journal of Thermal Analysis and Calorimetry. 2010. V. 102. No 2. P. 541-548. DOI: 10.1007/s10973-0100871-0.

64. Lucassen A., Beyer M., Zakel S. Journal of Loss Prevention in the Process Industries. 2019. V. 62. 103923 (4 p.). DOI: 10.1016/j.jlp.2019.103923. 